\title{
Domino Liver Transplantation: Current Status
}

\author{
Inês Barros ${ }^{1 *}$, Élia Mateus ${ }^{1,2}$, João Santos Coelho ${ }^{1,2}$, Américo Martins ${ }^{1,2}$, Eduardo Barroso ${ }^{1,2}$, \\ Fernando Nolasco ${ }^{1,2}$, Hugo Pinto-Marques ${ }^{1,2}$
}

\author{
*Corresponding author: \\ Inês Barros, MD \\ Hepato-Biliary-Pancreatic and \\ Transplantation Center \\ Curry Cabral Hospital \\ Lisbon's Central Hospitals \\ E-mail: inesfigueiredodebarros@gmail.com
}

\author{
'Hepato-Biliary-Pancreatic and Transplantation Centre, Curry Cabral Hospital \\ Lisbon's Central Hospitals and University Center, Portugal \\ ${ }^{2}$ NOVA Medical School, Lisbon, Portugal
}

\section{ABSTRACT}

Domino Liver transplant (DLT) is a strategy to address organ shortage and expand the liver donor pool for liver transplantation. Despite offering some unique technical challenges, DLT appears to be a safe and reasonable option to be considered for selected patients who would otherwise not benefit from liver transplantation. However, the benefit of expanding the donor pool must be balanced against the risk of disease transmission.In this review, we present where the DLT currently stands worldwide and our own experience with this procedure.

Key words: liver transplantation, domino liver transplantation, familial amyloidotic polyneuropathy, de novo amyloid polyneuropathy

\section{INTRODUCTION}

Orthotopic Liver transplantation (OLT) is an important therapeutic option for patients in a variety of acute and chronic liver diseases. However, the number of organs available for transplant is not enough to supply the demands of the ever increasing waiting list $(1,2,3)$. Domino Liver transplant (DLT) is a strategy to address organ shortage and expand the liver donor pool for liver transplantation $(4,5)$.

This technique was first performed in 1994, in Portugal and allows the explanted liver from one patient to be used in another patient $(6,7)$. The rationale behind this is that some metabolic disorders which can be corrected by liver transplantation leave a structurally normal and well-functioning liver that can be used in another patient $(8,9,10)$.

\section{Familial amyloid polyneuropathy}

Familial amyloid polyneuropathy (FAP) is an autosomal-dominant hereditary systemic disease that leads to progressive sensory-motor polyneuropathy $(11,12)$.

Transthyretin (TTR) protein is primarily synthesized in the liver and mutations in TTR gene leads to the formation, aggregation and accumulation of insoluble amyloid fibrils in other organs. To date, over 120 
TTR mutation have been described, the most common being the Val30Met mutation $(13,14)$. The deposition of amyloid fibrils leads to progressive loss of superficial sensation, severe autonomic dysfunctions, and cardiac conduction disturbances $(15,16)$.

Since over $90 \%$ of TTR Met 30 is produced within the liver, LT will halt disease progression and clinical manifestations $(17,18,19)$.

FAP livers have a normal anatomy and show no abnormal function other than producing variant TTR. FAP patients are usually young, which in combination with a short cold ischemia time, allows excellent conditions for the liver to be used as a graft $(10,20)$.

Medical treatment of patients with TTR mutationFAP involves disease-modifying targeted therapy to prevent further production of amyloid deposits $(21,22)$. Tafamidis, the most commonly used drug, kinetically stabilizes mutant TTR tetramers and prevents their dissociation into monomers. However, although there is evidence for its effectiveness in delaying neurological impairment, Tafamidis does not seem to halt the progression of FAP entirely. Therefore, liver transplantation (LT) remains a valid treatment option for many patients $(15,23,24)$.

\section{Domino liver recipients}

Indications for DLT vary between countries and must take into account factors including age, potential hazards, probability of recurrence, prognosis and priorities in the transplant waiting lists. Many centers select older and more marginal transplant candidates for DLT (25). By December 31, 2017, a total of 1254 domino transplantations were registered in FAP World Transplant Registry. Mean domino recipient age was $55.7 \pm 10.2$ years, with a median of 57.1 years. Main indications for the DLT recipients included: primary hepatic malignancy $(41.4 \%)$, alcoholic cirrhosis (19\%), cirrhosis secondary to hepatitis B and/or C (17\%), metastatic hepatic malignancy (2.3\%) and retransplantation (5.3\%). (http://www.fapwtr.org)

It is important that the domino recipient is aware of the possibility of developing "de novo" FAP disease. Patients must be assured that, if necessary, they will have the opportunity to receive a cadaveric graft after wards $(26,27)$.

\section{Operative/technical considerations in domino liver transplantation}

Classic DLT involves resection of the inferior vena cava (IVC) in the FAP patient, which requires venove- nous bypass, because FAP patients are particularly sensitive to hemodynamic changes after caval clamping. In Lisbon, Pena and Barroso developed the 'Double Piggy-back' technique, that allows preservation of the donor's IVC without the need of caval clamping or bypass. This technique was first performed by our group in 2001 (28).

The fundamental rule in total hepatectomy in the PAF patient is to avoid unnecessary mobilizations that may contribute to small periods of warm ischemia. The hilum is minimally dissected, and the common bile duct is divided at its mid length. Cholecystectomy is also performed. Then, the liver is mobilized and freed from the IVC. Accessory hepatic veins greater than $5 \mathrm{~mm}$ in diameter are preserved if clamping results in congestion of part of the liver. The right hepatic vein (RHV) and the cuff of middle (MHV) and left hepatic (LHV) veins are isolated. After dissection, the proper hepatic artery is divided at the bifurcation of gastroduodenal and common hepatic arteries, and the portal vein is divided $1 \mathrm{~cm}$ below its bifurcation. The RHV is transected close to the liver parenchyma using a vascular stapler. The isolated M-LHV cuff is double clamped and hepatic veins are then divided close to the liver surface, completing total hepatectomy. The explanted liver is then perfused with preservation solution through the portal vein and the hepatic artery after opening the RHV stapler line $(28,29)$.

The "Double Piggy-back" technique offers unique technical challenges, since vessels are shared between the donor and the FAP graft. To overcome the problem of short vascular stumps, many techniques of outflow reconstruction of the domino graft have been reported. Graft options to create a "neo" suprahepatic IVC include the use of a cadaveric IVC with or without renal vein, iliac veins, and pulmonary artery, among others. The reconstruction will allow the surgeon to perform the domino liver transplant in a standard piggyback fashion $(30,31,32)$ (fig. 1).

\section{Long-term results after domino liver transplantation}

DLT is not associated with a higher morbidity or mortality rate in the donor. However, the recipient carries the risk of developing "de novo" FAP disease $(33,34)$.

Early in the development of the technique and according to the natural history of FAP disease, it was assumed that the development of the disease would only become clinically apparent 25 or 30 years after DLT. However, there were concerns about the impact of 


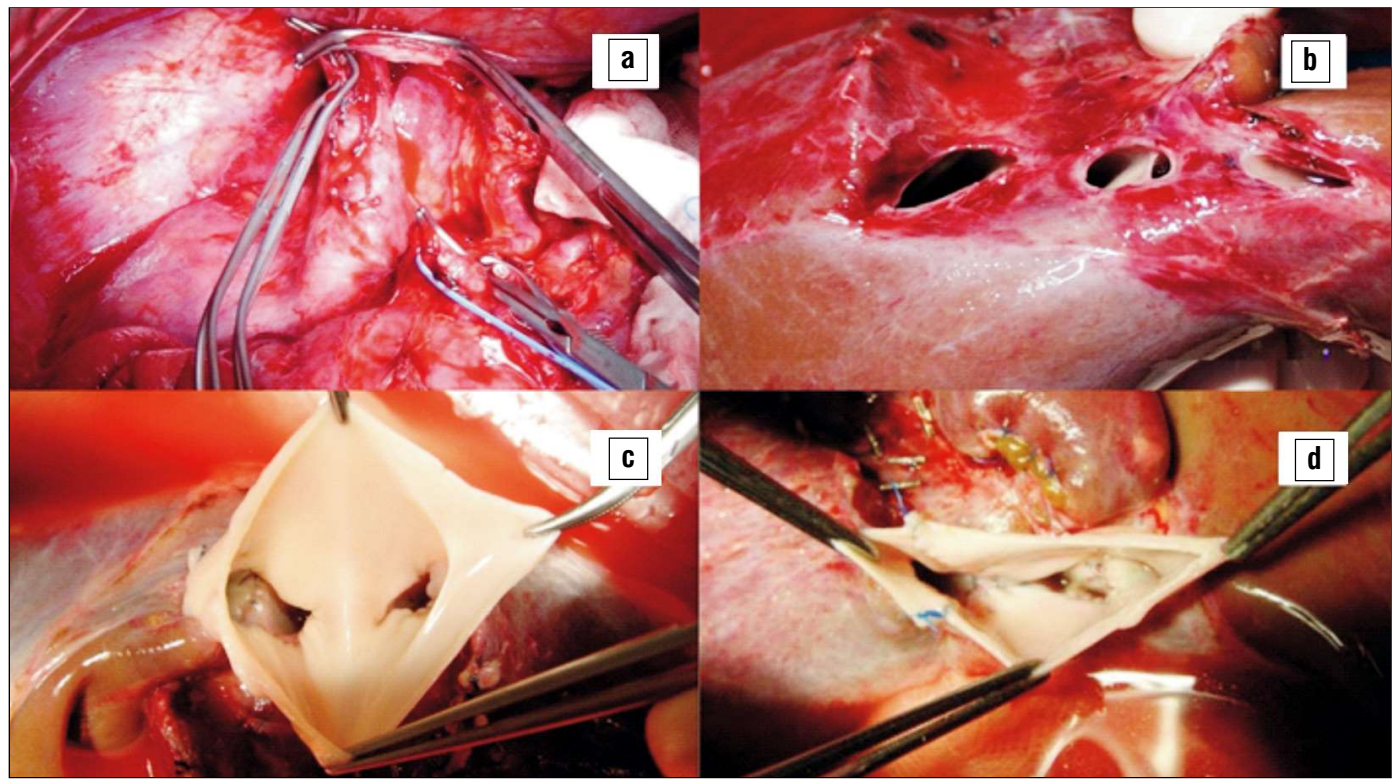

Figure 1 - a: Abdominal cavity after hepatectomy in a FAP liver donor; $b$ : Orifices of the hepatic veins; c,d: "neo" suprahepatic inferior vena cava

the recipient's age and post-transplant immunosuppression on the underlying biological mechanisms and their possible contribution to the earlier development of symptoms in DLT recipient $(34,35)$. Indeed, several subsequent papers described the development of acquired FAP earlier than previously anticipated $(26,28,36)$. In one study from France, 4 of the 91 patients (4.5\%) who underwent a DLT with a FAP liver developed "de novo" amyloid polyneuropathy proven by nerve biopsy after a mean delay of 5.75 years (37). A Spanish study describes "de novo" amyloidosis appearing 6-8 years after DLT in 4 out of 31 patients (12.9\%). One study from Portugal by our own group, reports that 13 of the 114 patients (11.4\%) submitted to DLT developed "de novo" amyloidosis with a median elapsed time until the appearance of clinical features of 75 months (60-121 months) $(28,38)$.

Domino recipients should be maintained on lifelong follow-up and consideration of standardized screening protocols for acquired amyloid in DLT recipients are warranted to develop a management strategy for "de novo" amyloid polyneuropathy (39). Once iatrogenic amyloid neuropathy and systemic amyloidosis are diagnosed, treatment options are limited and retransplantation with a non-domino liver should be considered. However, retransplantation is considered to be a high-risk procedure, due to the comorbidities of patients and the surgical challenges in an already transplanted patient $(26,36,40)$.

While the risks of DLT are unique, several studies suggest that they do not contribute to an elevated mortality rate as compared to receiving organs from deceased donors. In the Domino Liver World Transplant Register, the overall 1-year, 5-year, and 8-year graft survival in DLT recipients was $79.9 \%, 65.3 \%$, and $61.6 \%$, respectively. Also, several studies found no difference in the rates of acute rejection, perioperative bleeding, vascular complications or biliary complications between domino transplant recipients and cadaveric transplant recipients $(8,41,42,43)$.

\section{Experience with DLT at Curry Cabral Hospital, Portugal}

From July 2001 to October 2020, 337 patients underwent a DLT with a FAP liver in our center. The population was composed of 271 men (80.3\%) and 66 women (19.7\%) with a median age at the time of LT of 57 years. Main indications for the DLT recipients are described in table 1. After a median follow-up of 108

Table 1 - Demographic characteristics and indications for liver transplantation in FAP liver recipients

\begin{tabular}{lc}
\hline & $\begin{array}{c}\text { FAP liver recipients } \\
(\mathbf{n}=\mathbf{3 3 7})\end{array}$ \\
\hline Demographic characteristics & $66(19.7 \%)$ \\
Female sex, $\mathrm{n}(\%)$ & $57[10]$ \\
Age (years), median [IQR] & \\
\hline Main indications for liver transplantation, $\mathrm{n}(\%)$ & $147(43.6 \%)$ \\
Primary hepatic malignancy & $81(24 \%)$ \\
Alcoholic cirrhosis & $53(15.7 \%)$ \\
Cirrhosis secondary to hepatitis B and/or C & $6(1.8 \%)$ \\
Metastatic hepatic malignancy & $15(4.5 \%)$ \\
Retransplantation & \\
\hline
\end{tabular}


Table 2 - Evaluation and monitoring of "de novo" amyloidosis after domino liver transplantation

\begin{tabular}{lc}
\hline & $\begin{array}{c}\text { FAP liver recipients } \\
(\mathbf{n}=337)\end{array}$ \\
\hline Clinical signs of acquired FAP & $85(25.2 \%)$ \\
$\quad$ Neuropathic pain, lack of sensibility, $\mathrm{n}(\%)$ & $19(5.6 \%)$ \\
$\quad$ Diarrhea, $\mathrm{n}(\%)$ & $14(4.2 \%)$ \\
$\quad$ Weight loss, $\mathrm{n}(\%)$ & $108[40]$ \\
\hline Time until the appearance of clinical features & $62(18.4 \%)$ \\
(months), median [IQR] & $55(16.3 \%)$ \\
\hline \begin{tabular}{l} 
Electromyographic evidence of polyneuropathy, $\mathrm{n}(\%)$ \\
\hdashline Demonstration of amyloid deposits in a tissue biopsy,
\end{tabular} & \\
$\mathrm{n}(\%)$ & \\
\hline
\end{tabular}

months (35-163 months), 85 patients (25.2\%) developed clinical signs of FAP disease, most commonly neuropathic pain, lack of sensibility, diarrhea or weight loss. 62 (18.4\%) had disease confirmation after repeated neurological assessment and electro-myography. Amyloid deposition was demonstrated in 55 patients either by labial salivary gland, sural nerve, rectal, renal or fat biopsy (table 2). 20 of these patients with acquired FAP underwent retransplantation with a cadaveric donor liver. Although in 3 patients the symptoms worsened, 9 of the 20 patients (45\%) reported some improvement.

\section{CONCLUSION}

In the light of current knowledge, DLT remains a good option in carefully selected patients. Given the known risk of FAP disease transmission, the selection of DLT recipients must consider the status of the patient 7-8 years after transplantation, if a retransplant is necessary. Since acquired polyneuropathy occurs earlier than anticipated, DLT could be considered for extended indications and according to the feasibility of a retransplant.

\section{Conflicts of interest: none}

\section{Ethics of approval: none}

\section{REFERENCES}

1. Ishigami $M$, Honda $T$, Kuzuya $T$, Ishizu $\mathrm{Y}$, Ito $\mathrm{T}$, Kamei $\mathrm{H}$, et al. Revisiting the indications for liver transplantation in cirrhotic patients considering the long-term outcomes of cirrhotic patients. J Hepatobiliary Pancreat Sci. 2020;27(9):655-662.

2. Mahmud N. Selection for Liver Transplantation: Indications and Evaluation. Curr Hepatol Rep. 2020;1-10.

3. Nunes F, Valente M, Pereira R, Amil M. Domino liver transplant: influence on the number of donors and transplant coordination. Transplant Proc. 2004;36(4):916-7.

4. Marín-Gómez LM, Gómez-Bravo MA, Barrera-Pulido L, BernalBellido C, Alamo-Martínez JM, Suárez-Artacho G, et al. Outcomes of
Domino Liver Transplantation: A Single Institution's Experience. Transplant Proc. 2010;42(2):644-6.

5. Carrera M, Bogue E, Schiano T. Domino liver transplantation: a practical option in the face of the organ shortage. Prog Transplant. 2003;13(2):151-3.

6. Marques HP, Barros I, Li J, Murad SD, di Benedetto F. Current update in domino liver transplantation. Int J Surg. 2020;82S:163-168.

7. Kitchens WH. Domino liver transplantation: indications, techniques, and outcomes. Transplant Rev (Orlando). 2011;25(4):167-77.

8. Wilczek HE, Larsson M, Yamamoto S, Ericzon BG. Domino liver transplantation. J Hepatobiliary Pancreat Surg. 2008;15(2):139-48.

9. Celik N, Squires JE, Soltys K, Vockley J, Shellmer DA, Chang W, et al. Domino liver transplantation for select metabolic disorders: expanding the living donor pool. JIMD Rep. 2019;48(1):83-89.

10. Azoulay D, Salloum C, Samuel D, Planté-Bordeneuve V. Operative risks of domino liver transplantation for the FAP liver donor and the FAP liver recipient. Amyloid. 2012;19 Suppl 1:73-4.

11. Ueda M, Ando Y. Recent advances in transthyretin amyloidosis therapy. Transl Neurodegener. 2014;3:19.

12. Koike $\mathrm{H}$, Katsuno M. Transthyretin Amyloidosis: Update on the Clinical Spectrum, Pathogenesis, and Disease-Modifying Therapies. Neurol Ther. 2020;9(2):317-333. Epub 2020 Sep 18.

13. Luigetti M, Romano A, Di Paolantonio A, Bisogni G, Sabatelli M. Diagnosis and Treatment of Hereditary Transthyretin Amyloidosis (hATTR) Polyneuropathy: Current Perspectives on Improving Patient Care. Ther Clin Risk Manag. 2020;16:109-123.

14. Escolano-Lozano F, Geber C, Barreiros AP, Birklein F. Follow-up in transthyretin familial amyloid polyneuropathy: Useful investigations. J Neurol Sci. 2020;413:116776. Epub 2020 Mar 18.

15. Sekijima Y, Ueda M, Koike H, Misawa S, Ishii T, Ando Y. Diagnosis and management of transthyretin familial amyloid polyneuropathy in Japan: red-flag symptom clusters and treatment algorithm. Orphanet J Rare Dis. 2018;13(1):6.

16. Cakar A, Durmus-Tekce H, Parman Y. Familial Amyloid Polyneuropathy. Noro Psikiyatr Ars. 2019;56(2):150-156.

17. Wilczek HE, Larsson M, Yamamoto S, Ericzon BG. Domino liver transplantation. J Hepatobiliary Pancreat Surg. 2008;15(2):139-48.

18. Monteiro E, Freire A, Barroso, E. Familial amyloid polyneuropathy and liver transplantation. J Hepatol. 2004;41(2):188-94.

19. Sousa MM, Ferrăo J, Fernandes R, Guimarăes $A$, Geraldes JB, Perdigoto $R$, et al. Deposition and passage of transthyretin through the blood-nerve barrier in recipients of familial amyloid polyneuropathy livers. Lab Invest. 2004;84(7):865-73.

20. Furtado AJ. L. Domino liver transplantation using FAP grafts. HUC experience - hopes and realities. Amyloid. 2003;10 Suppl 1:84-7.

21. Müller ML, Butler J, Heidecker B. Emerging therapies in transthyretin amyloidosis - a new wave of hope after years of stagnancy? Eur J Heart Fail. 2020;22(1):39-53.

22. Ines M, Costa J. Survival in Transthyretin Familial Amyloid Polyneuropathy: A Review. J. Neurol. Neuromedicine. 2019;4: 22-25.

23. Russo M, Gentile L, Toscano A, M'Hammed Aguennouz, Vita G, Mazzeo A. Advances in Treatment of ATTRv Amyloidosis: State of the Art and Future Prospects. Brain Sci. 2020;10(12):952.

24. Kavousanaki M, Tzagournissakis M, Zaganas I, Stylianou KG, Patrianakos AP, Tsilimbaris MK, et al. Liver Transplantation for Familial Amyloid Polyneuropathy (Val30Met): Long-Term Follow-up Prospective Study in a Nontransplant Center. Transplant Proc. 2019; 51(2):429-432.

25. Kitchens WH. Domino liver transplantation: indications, techniques, and outcomes. Transplant Rev (Orlando). 2011;25(4):167-77.

26. Mnatsakanova D, Živkovic SA. latrogenic amyloid polyneuropathy after domino liver transplantation. World J Hepatol. 2017; $9(3): 126-130$

27. Conti F, Mochel F, Calmus Y. Domino liver transplantation: the risk of disease recurrence. Clin Res Hepatol Gastroenterol. 2019;43(5): 510-512.

28. Marques HP, Ribeiro V, Almeida T, Aniceto J, Silva S, Sobral M, et al. Long-term results of domino liver transplantation for hepatocellular carcinoma using the 'Double Piggy-back' Technique: A 13-year experience. Ann Surg. 2015;262(5):749-56; discussion 756. 
29. Lerut J, Foguenne M, Lai Q, de Ville de Goyet J. Domino-liver transplantation: toward a safer and simpler technique in both donor and recipient. Updates Surg. 2021;73(1):223-232.

30. Qu W, Zhu ZJ, Wei L, Sun LY, Liu Y, Zeng ZG. Reconstruction of the Outflow Tract in Cross-Auxiliary Double-Domino Donor Liver Transplantation. Transplant Proc. 2016;48(8):2738-2741.

31. Popescu I, Dima S0. Domino liver transplantation: How far can we push the paradigm? Liver Transpl. 2012;18(1):22-8.

32. Cepeda-Franco C, Marín-Gómez LM, Bernal-Bellido C, SuárezArtacho G, Álamo-Martínez JM, Padillo-Ruiz FJ, et al. Alternative outflow reconstruction in domino liver transplantation. Liver Transpl. 2017;23(9):1226-1228.

33. Ericzon BG. Domino transplantation using livers from patients with familial amyloidotic polyneuropathy: should we halt? Liver Transpl. 2007;13(2):185-7.

34. Banerjee D, Roeker LE, Grogan M, Swiecicki P, Poterucha J, Heimbach J, et al. Outcomes of patients with familial transthyretin amyloidosis after liver transplantation. Prog Transplant. 2017;27(3): 246-250.

35. Furtado PAJL. Domino transplantation using livers from patients with familial amyloidotic polyneuropathy. Current Opinion in Organ Transplantation. 2000;5(2):69-73.

36. Yamamoto $\mathrm{S}$, Wilczek HE, Iwata $\mathrm{T}$, Larsson $\mathrm{M}$, Gjertsen $\mathrm{H}$, Söderdahl $\mathrm{G}$, et al. Long-term consequences of domino liver transplantation using familial amyloidotic polyneuropathy grafts. Transpl Int. 2007;20(11):926-33.
37. Adams D, Lacroix C, Antonini T, Lozeron P, Denier C, Kreib AM, et al. Symptomatic and proven de novo amyloid polyneuropathy in familial amyloid polyneuropathy. Amyloid. 2011;18 Suppl 1:174-7.

38. Lladó L, Baliellas C, Casasnovas C, Ferrer I, Fabregat J, Ramos E, et al. Risk of transmission of systemic transthyretin amyloidosis after domino liver transplantation. Liver Transpl. 2010;16(12):1386-92.

39. Bolte FJ, Schmidt HHJ, Becker T, Braun F, Pascher A, Klempnauer J, et al. Evaluation of domino liver transplantations in Germany. Transpl Int. 2013;26(7):715-23.

40. Vieira H, Rodrigues C, Pereira L, Jesus J, Bento C, Seco C, et al. Liver retransplantation in patients with acquired familial amyloid polyneuropathy: a Portuguese center experience. Transplant Proc. 2015;47(4):1012-5.

41. Sebagh M, Yilmaz F, Karam V, Falissard B, Ichaï P, Roche B, et al. Cadaveric full-size liver transplantation and the graft alternatives in adults: A comparative study from a single centre. J Hepatol. 2006; 44(1):118-25.

42. Bispo M, Marcelino P, Pinto Marques $H$, Martins A, Perdigoto R, Joăo Aguiar M, et al. Domino versus deceased donor liver transplantation: Association with early graft function and perioperative bleeding. Liver Transpl. 2011;17(3):270-8.

43. Geyer ED, Burrier C, Tumin D, Hayes Jr D, Black SM, Washburn WK, et al. Outcomes of domino liver transplantation compared to deceased donor liver transplantation: a propensity-matching approach. Transpl Int. 2018;31(11):1200-1206. 